\title{
Optimal Grid-Connected PV System for a Campus Microgrid
}

\author{
M. Reyasudin Basir Khan ${ }^{1}$, Jagadeesh Pasupuleti ${ }^{2}$, Jabbar Al-Fattah $^{3}$, Mehrdad Tahmasebi ${ }^{4}$ \\ ${ }^{1}$ Universiti Kuala Lumpur, British Malaysian Institute, Jalan Sg Pusu, 53100 Gombak, Selangor, Malaysia \\ ${ }^{2}$ Universiti Tenaga Nasional, Jalan IKRAM-UNITEN, 43000 Kajang, Selangor, Malaysia \\ ${ }^{3}$ Universiti Tun Hussein Onn Malaysia (UTHM), 86400 Parit Raja, Batu Pahat Johor, Malaysia \\ ${ }^{4}$ Department of Electrical Engineering, Eyvan-e-Gharb Branch, Islamic Azad University, Eyvan, Iran
}

\begin{tabular}{l}
\hline \hline Article Info \\
\hline Article history: \\
Received May 21, 2018 \\
Revised Jun 27, 2018 \\
Accepted Aug 20, 2018
\end{tabular}

\section{Keywords:}

HOMER

Microgrid

Optimal hybrid system

Renewable energy

\begin{abstract}
This paper discusses on the implementation of a grid-connected PV system for university campus in Malaysia. The primary goal of this study is to develop a grid-connected microgrid comprises of Photovoltaic (PV) and a battery storage system to meet the campus load demand and minimize grid dependency. The microgrid modeled and simulated in Hybrid Optimization Model for Electrical Renewable (HOMER) software. Actual load profile and renewable resources were used as an input parameter for the hybrid system. The campus selected is Universiti Kuala Lumpur, British Malaysian Institute as it represents typical load profile for a small campus. Therefore, the results can be used to represent hybrid system development for other small campuses in Malaysia as well. Firstly, optimal sizing of renewable energy (RE) were simulated with respect to total Net Present Cost (NPC) and Cost of Energy (COE). Then, sensitivity analysis conducted to determine the system performance based on changes of load growth, and renewable resources. The results demonstrate optimal HRES combinations for the campus microgrid comprises of $50 \mathrm{kWp}$ of PV generations with $50 \mathrm{~kW}$ inverter. However, inclusion of $576 \mathrm{kWh}$ battery storage system will increase the NPC but has higher RE penetration.
\end{abstract}

Copyright $@ 2018$ Institute of Advanced Engineering and Science. All rights reserved.

\section{Corresponding Author:}

M. Reyasudin Basir Khan,

Universiti Kuala Lumpur, British Malaysian Institute,

Jalan Sg Pusu, 53100 Gombak, Selangor, Malaysia.

Email: reyasudin@gmail.com

\section{INTRODUCTION}

Hybrid Renewable Energy System (HRES) is a combination of multiple renewable sources in a microgrid for electricity supply in an area [1]. It can operate either in standalone or grid-connected modes. Typically, standalone modes are used in remote or rural areas where grid connection is uneconomical [2]. In this mode, the renewable generation supported by tradisional generations such as diesel and battery storage system. On the other hand, grid-connected modes normally used in buildings, factories and residential area. In this mode, the hybrid renewable sources will meet the load demand and sells the excess energy to the grid.

Technical and economic analysis is crucial for efficient utilization of a HRES in a microgrid. There are many software tools has been used to evaluate and analyse electrical, economical, and environmental performance of a HRES such as HOMER [3], H2RES [4], RETScreen [5] and EnergyPlan [6]. This study uses HOMER software for optimal hybrid sytems design. Many researchers were found utilizing HOMER for hybrid system optimizations. For example, Laith M. Halabi et al uses HOMER to design a hybrid system in a remote village in Malaysia [7]. Their hybrid system design includes site survey alongside detailed technical-economic analysis for both on-grid and off-grid connections of a PV-Wind-diesel-battery system. Moreover, Khan et al uses HOMER to investigate the optimal hybrid system combinations in a tourism island located in the South China Sea [8], [9]. Actual load profiles and renewable sources of were 
used in the study to evaluate different combination of renewable energy generations. Mohammad Mohammadi et al. presents a hybrid renewable system with PV and wind without conventional generation systems for a residential house in Tehran, Iran [10]. HOMER software was used to evaluate the system costs and greenhouse gasses emissions. Additionally, Samir M. Dawoud et al. modeled hybrid system comprises of PV and wind turbines for a remote area in Egypt [11]. Meanwhile, Asad Waqar et al. uses HOMER to minimize the $\mathrm{CO}_{2}$ emission in a microgrid with Vehicle-to-grid (V2G) storage [12]. On the other hand, N.A. Jefry et al. integrates renewable energy generations in a Demand Response Program for buildings in Universiti Tun Hussein Onn, Malaysia campus [13]. HOMER was used to identify the technical and economics viability of the system.

Other advanced methods also been used by researchers to determine the optimal combinations of hybrid system in a microgrid. For instance, Yashwant Sawle et al. uses multi-objective function to determine the optimal design of a microgrid system [14]. Meanwhile, Abdelhamid Kaabeche et al. uses Firefly-inspired algorithm to determine optimal size HRES for an area in Algeria [15]. Many other advanced methods also used for optimal hybrid system sizing such as Genetic Algorithm [16], Particle Swarm Optimization [17], [18], Fuzzy [19] and Artificial Neural Network [20]. In this study, the HRES for a University campus were modeled in HOMER and results such as NPC, $\mathrm{COE}$ and $\mathrm{CO}_{2}$ emission were assessed.

The rest of the paper are organized as follows: Section 2 describes the data collection for this study such as renewable sources and load profile. Section 3 presents the HRES modeled in HOMER that includes input parameters and specifications. Section 3 also demonstrates the results of HRES optimization and sensitivity analysis. Finally, Section 4 provides conclusion and summarizes the contribution of this study.

\section{DATA COLLECTION}

Universiti Kuala Lumpur, British Malaysian Institute located at $3^{\circ} 15^{\prime} 4^{\prime \prime} \mathrm{N}$ latitude and $101^{\circ} 43^{\prime} 41^{\prime \prime} \mathrm{E}$ longitude. The campus located in West Malaysia and has typical equatorial climate with hot and humid throughout the year. The data collected for this study comprises of solar irradiance, temperature and load profile.

\subsection{Load Profile}

Figure 1 shows the daily and monthly load profile of the campus. The peak demand occurs in the morning and late evening. This is due to the usage of electricity in offices, lecture halls and rooms in the morning. Meanwhile, in the evening, the rise of energy usage is mainly contributed by the student apartment. The energy usage highly contributed by PC and other equipments in student rooms.

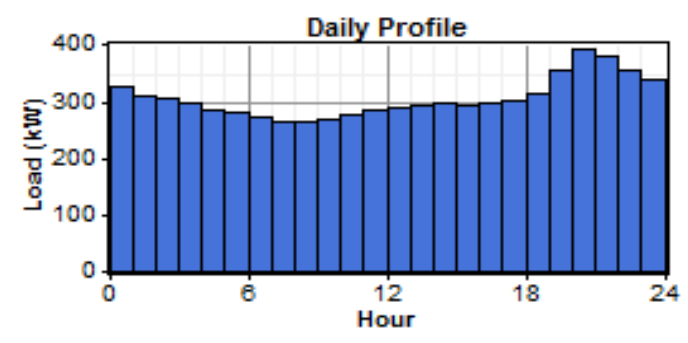

(a)

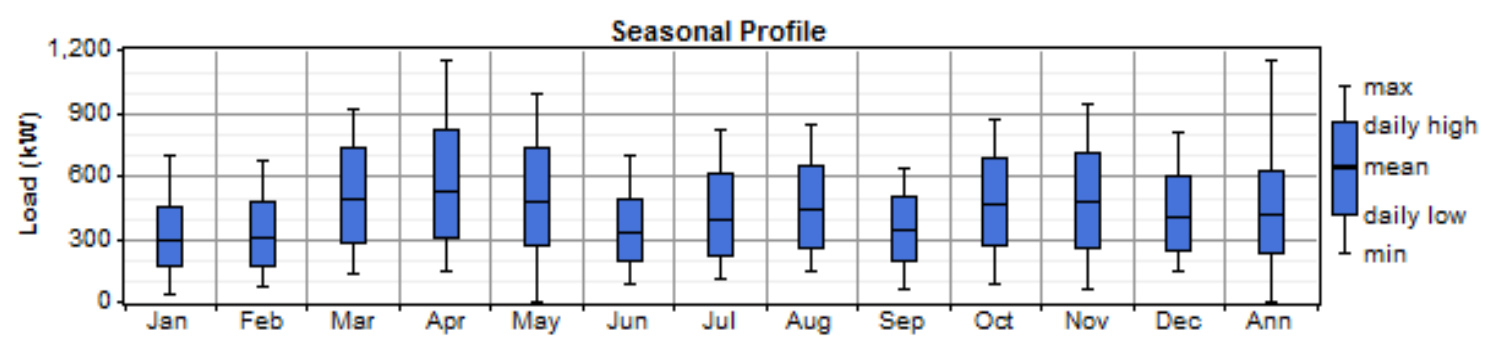

(b)

Figure 1. a) Daily solar radiation profile, b) Monthly solar radiation profile 


\subsection{Solar Radiation}

The amount of solar radiation received in the location is crucial for installation of a PV system. The solar radiation data for three years used for this study (2015-2017), where the data was obtained from NASA POWER database. The solar radiation profile throughout the years were investigated to determine the feasibility of PV system installation. Figure 2 shows the solar daily and monthly solar radiation profile for the campus.

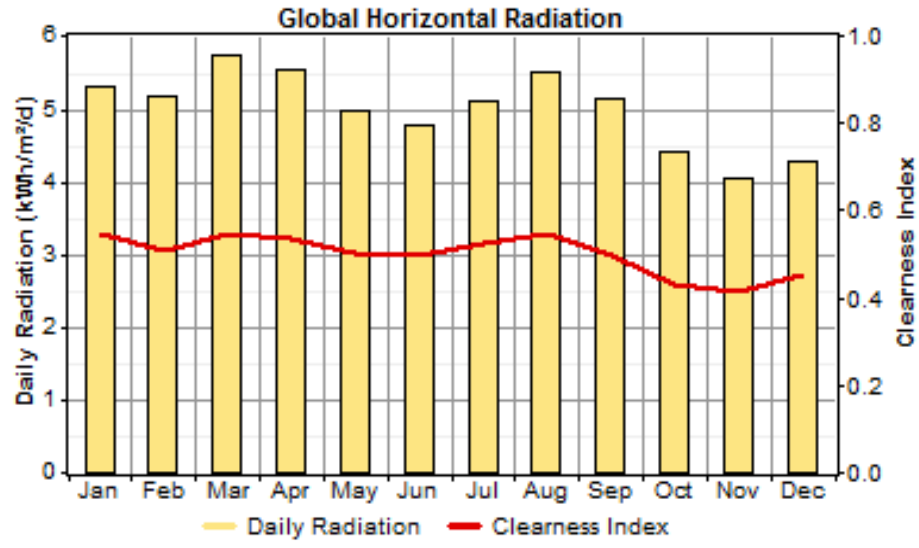

Figure 2. Daily Solar Radiation Profile

\subsection{Temperature}

The performance of PV system at site highly effected by the temperature variations. Therefore, temperature effect on PV panels also simulated to have PV system performance that closely matched the site conditions. Three year of temperature data (2015-2017) was used for this study.

\section{TECHNO-ECONOMIC ANALYSIS}

The input parameters used for this study includes the hourly solar radiation, temperature and load profile as discussed in Section 2. Moreover, the economic analysis includes parameters such as project lifetime of 25 years and annual interest rates. The current annual interest rates for Malaysia in May 2018 is $3.28 \%$.

\subsection{HOMER Model and Components}

The grid connected hybrid system model comprises of four main components such as PV, inverter and battery storage system. The HOMER model is illustrated in Figure 3 and the components specifications are shown in Table 1. The economic analysis such as cost for this study is simulated in USD (US Dollar).

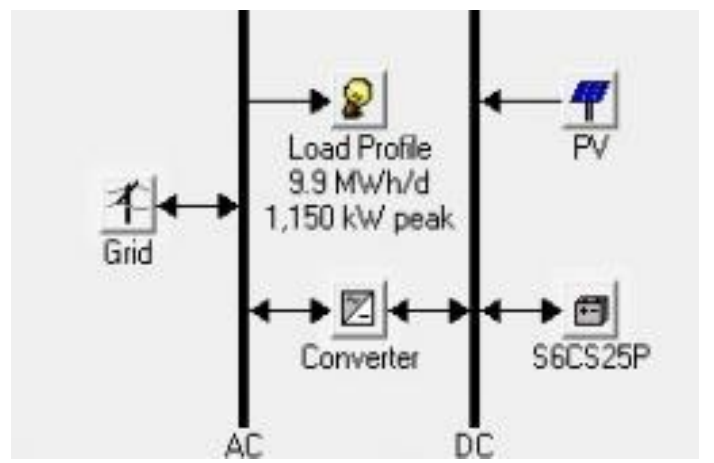

Figure 3. Hybrid system model in HOMER 


\subsubsection{PV Systems}

The PV system size varied from $0 \mathrm{~kW}$ to $500 \mathrm{~kW}$ with $50 \mathrm{~kW}$ step size. The size variation of PV system is to ensure optimal size chosen in HOMER optimization analysis. The PV system costs comprises of both PV modules and Balance of Systems (BOS) that covers labour and mounting costs. This study also considers economics of scale to illustrate the impact of system size in respective to the cost.

\subsubsection{Battery Storage System}

The PV system size varied from $1 \mathrm{~kW}$ to $500 \mathrm{~kW}$ with $50 \mathrm{~kW}$ step size. The size variation of PV system is to ensure optimal size chosen in HOMER optimization analysis.

\subsubsection{Grid}

The grid is the primary source of electricity for the campus complemented by PV system. The rate defined for this study is $\$ 0.01 / \mathrm{kWh}$ price and $\$ 0.05 / \mathrm{kWh}$ sellback. The same rate used for all weeks with $632 \mathrm{~g} / \mathrm{kWh}$ of $\mathrm{CO}_{2}$ emission factors.

\begin{tabular}{|c|c|c|}
\hline No & Components & Specifications \\
\hline \multirow[t]{6}{*}{1} & PV System [21] & \\
\hline & Size considered $(\mathrm{kW})$ & $0,50,100,200,250,300,350,400,450,500$ \\
\hline & Capital cost $(\$ / \mathrm{W})$ & 3.64 \\
\hline & Replacement cost $(\$ / \mathrm{W})$ & 3.64 \\
\hline & Operation and maintenance cost (\$/year) & 329 \\
\hline & Lifetime (Years) & 25 \\
\hline \multirow[t]{5}{*}{2} & Inverter [21] & \\
\hline & Size considered $(\mathrm{kW})$ & $0,100,150,200,250,300,350,400,450,500$ \\
\hline & Capital cost $(\$ / \mathrm{W})$ & (2) \\
\hline & Replacement cost $(\$ / \mathrm{W})$ & 1.05 \\
\hline & Operation and maintenance cost $(\$)$ & 10,500 \\
\hline \multirow[t]{7}{*}{3} & Batteries [9] & \\
\hline & Model & Surrette $6 \mathrm{CS} 25 \mathrm{P}(6 \mathrm{~V}, 1156 \mathrm{Ah})$ \\
\hline & Batteries per string & 83 \\
\hline & Sizes considered & $0,1,2,3,4,5$ \\
\hline & Capital cost (\$/battery) & 1,200 \\
\hline & Replacement cost (\$/battery) & 1,200 \\
\hline & Operation and maintenance cost (\$/year) & 10 \\
\hline
\end{tabular}

\subsection{Controller and Energy Management Systems}

Both Load Following (LF) and Cycle Charging (CC) are considered by HOMER for optimal energy management in the mcicrogrid. Best strategy will be chosen by HOMER based on minimal cost and high RE generations.

\subsection{Optimization Results}

The system optimal configurations sorted by HOMER based on the NPC. The optimal systems for the campus hybrid PV system is illustrated in Table 2. The results cover technical specifications such as sizes, capital cost, NPC, COE and renewable fraction (RF).

Table 2. Technical and Economic Specifications for grid-connected hybrid system

\begin{tabular}{llllllllll}
\hline Rank & $\begin{array}{l}\text { PV } \\
(\mathrm{kW})\end{array}$ & Battery & $\begin{array}{l}\text { Conv. } \\
(\mathrm{kW})\end{array}$ & $\begin{array}{l}\text { Grid } \\
(\mathrm{kW})\end{array}$ & $\begin{array}{l}\text { Dispatch } \\
\text { Strategy }\end{array}$ & $\begin{array}{l}\text { Initial capital } \\
(\$)\end{array}$ & $\begin{array}{l}\text { NPC } \\
(\$)\end{array}$ & $\begin{array}{l}\text { COE } \\
(\$ / \mathrm{kWh})\end{array}$ \\
\hline 1 & 50 & 0 & 50 & 1000 & CC & 198,944 & $6,374,048$ & 0.102 \\
2 & 0 & 83 & 50 & 1000 & CC & 95,896 & $6,789,664$ & 0.103 \\
3 & 50 & 83 & 50 & 1000 & CC & 249,452 & $6,831,080$ & 0.104 & 0.03 \\
\hline
\end{tabular}

All system configurations listed utilizes cycle charging as an optimal dispatch strategy. The most optimal hybrid system configuration is $50 \mathrm{~kW}$ PV system with no battery storage followed by battery only system and hybrid PV-battery system. There is no total renewable energy solution for the campus due to generation limitation where RE sources unable to meet the demand. Moreover, the campus does not have the capacity for a large PV system installation, thus limiting to only $500 \mathrm{~kW}$ maximum capacity. 
The most optimal system has initial capital of \$ 198,944 with \$ 6,374,048 NPC and 0.102 \$/kWh of COE. The RE generation only contributes $3 \%$ from total generation. Battery only system with lower capital cost of $\$ 95,896$ shows promising results in term of reducing grid dependency. Although having lower capital cost, it has higher NPC and has no renewable energy contribution. The optimal PV system sizes followed by $50 \mathrm{~kW}$ PV system with battery storage. This system has capital cost of $\$ 249,452$ and $\$ 6,831,080$ NPC. This system has higher capital cost and NPC compared to other configurations due to integration of a battery storage system. However, this configuration shows promising results in high renewable energy contributions which is $3 \%$ from the total generations. The cost flow summary comparison of both PV only and PV system with battery storage is illustrated in Figure 4. The highest NPC contributed by the grid followed by PV for both hybrid configurations. The highest type of cost is the operating cost that contributes an average of $\$ 6,430,340$ and $\$ 6,490,360$ for grid-connected PV system and PV-battery system respectively. The initial capital needed for integration of $50 \mathrm{~kW}$ PV system is \$198,944 which includes \$153,556 for PV modules and $\$ 45,389$. The initial capital for installation of $720 \mathrm{kWh}$ battery storage system is $\$ 50,508$.
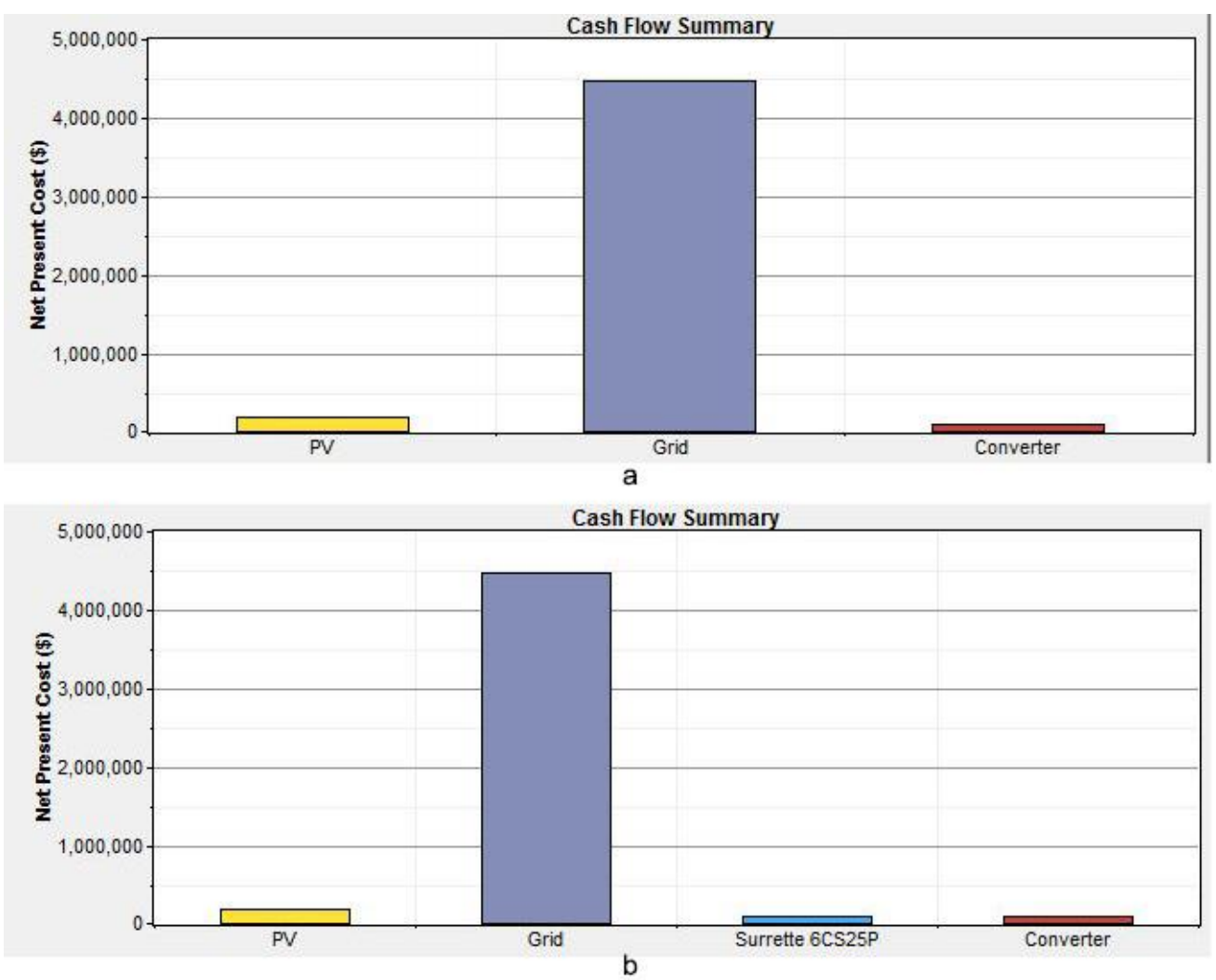

Figure 4. Cost summary comparison a) Grid-connected PV system, b) Grid-connected PV system PV system with battery storage

The estimated salvage for both systems is in year 25 . The average operation cost for both systems is $\$ 360,000 /$ year. Both systems has replacement cost for inverter charged at year 10 and year 20. However, for grid-connected PV-battery system has replacement cost for battery scheduled at year 12 and 24 . Since PV system has total lifetime of 25 year, only capital cost was considered.

The electrical productions for PV only system and PV with battery storage are similar. However, the comparison of system with PV generations and battery only system is shown in Figure 5. The PV system contributes $75,513 \mathrm{kWh}$ /year of generations from a total generation of 3,610,057 kWh/year. All optimal configurations do not have any excess electricity or unmet electric load.

The grid energy purchased for PV only system is \$3,534,544. Meanwhile, the energy purchased for PV-battery system is $\$ 3,534,239$. Both systems does not have any energy sell to the grid. Table 3 illustrates the total emission for each pollutant. The results show slightly lower $\mathrm{CO}_{2}$ emission for grid-connected PVbattery system compares to grid-connected PV system. 
Table 3. Total emissions for pollutants

\begin{tabular}{lcc}
\hline Pollutant & \multicolumn{2}{c}{ Emission (kg/year) } \\
& Grid-conneted PV system & Grid-connected PV-battery system \\
\hline Carbon dioxide & $2,233,832$ & $2,233,639$ \\
Carbon monoxide & 0 & 0 \\
Unburned hydrocarbons & 0 & 0 \\
Particulate matter & 0 & 0 \\
Sulfur dioxide & 9,685 & 9,684 \\
Nitrogen oxides & 4,736 & 4,736 \\
\hline
\end{tabular}

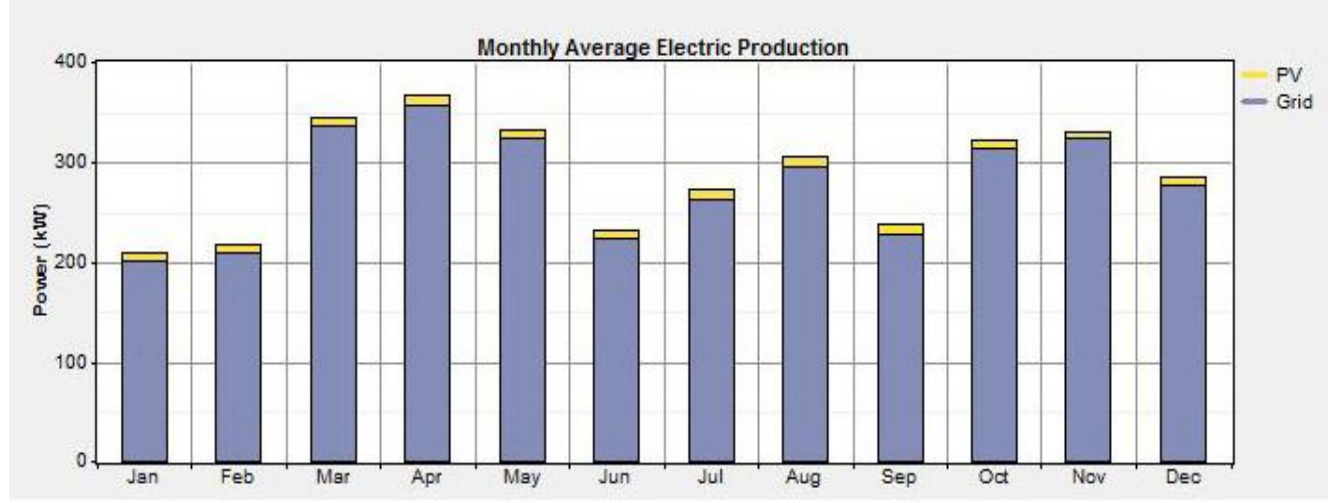

a

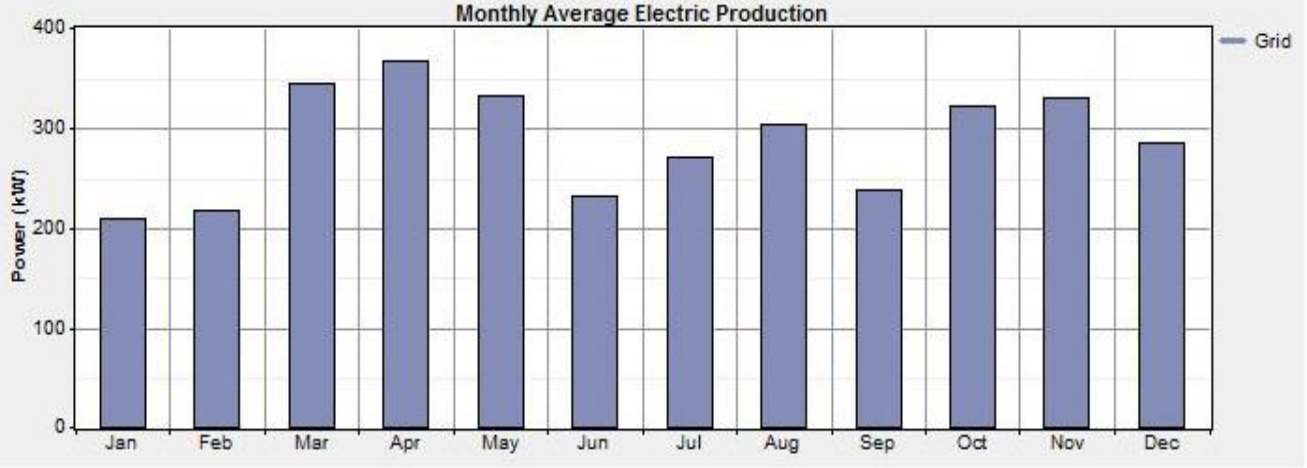

b

Figure 5. Monthly Electric Production a) PV integrated system b) Battery only system

\subsection{Sensitivity Analysis}

The sensitivity analysis was conducted to determine the output sensitivity towards variable changes. The sensitivity variables defined in this study is the annual average load profile. There were three values of annual average load defined in HOMER to simulate both increment and decrement of student occupation in the campus. The multiple average load values are $6,920 \mathrm{kWh} /$ day, $9,886 \mathrm{kWh} / \mathrm{day}, 12,852 \mathrm{kWh} /$ day and $14,829 \mathrm{kWh} /$ day. The variation of loads simulates $30 \%$ drops of student occupancies alongside $30 \%$ and 60 $\%$ rise of student population from nominal load of $9,886 \mathrm{kWh} /$ day. The variation of load profile versus total NPC and grid purchases is shown in Figure 6. The total NPC as well as grid purchases will increase as the load profile increases in the future. However, the PV system sizes does not vary where additional energy demand will be fulfilled by the grid only. Therefore, PV system size limited to $50 \mathrm{~kW}$ only for the campus microgrid. 


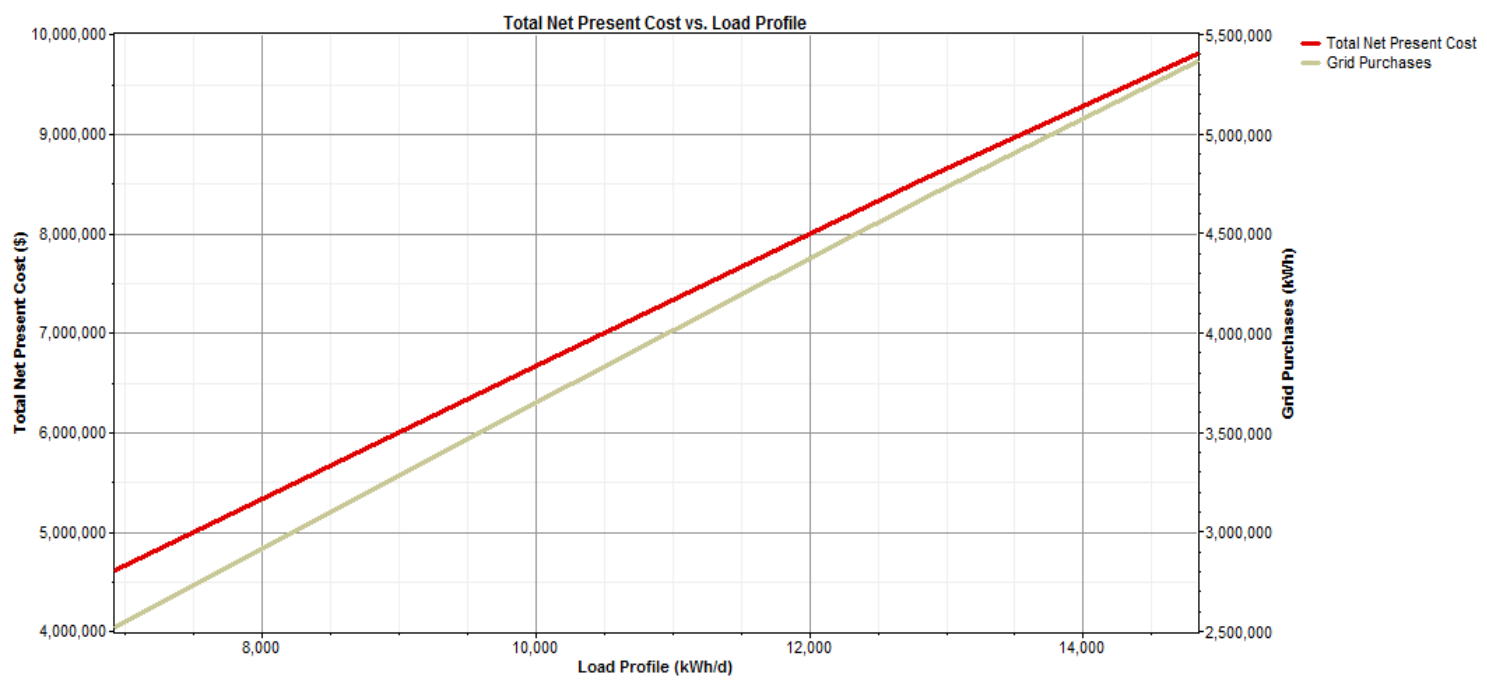

Figure 6. Sensitivity analysis total NPC against load profile variation.

\section{CONCLUSION}

There are two optimal systems for the campus microgrid based on techno-economic analysis in HOMER. The most optimal system is grid-connected PV system followed by grid-connected PV system with battery storage. Both systems show promising results in mitigating grid dependency but have discrepancy in renewable energy contribution. Although, PV system with battery storage have higher initial capital, NPC and COE compared to PV only system, it does provide less $\mathrm{CO}_{2}$ and higher RE penetration. Hence, both systems should be considered as the best option for PV system installation at this site.

\section{ACKNOWLEDGEMENTS}

The author would like to thank Universiti Kuala Lumpur and Universiti Tenaga Nasional (Grant no. J510050687) for supporting this research.

\section{REFERENCES}

[1] S. Bahramara, M. P. Moghaddam, and M. R. Haghifam, "Optimal planning of hybrid renewable energy systems using HOMER: A review,” Renew. Sustain. Energy Rev., vol. 62, pp. 609-620, 2016.

[2] Y. Sawle, S. C. Gupta, and A. K. Bohre, "Review of hybrid renewable energy systems with comparative analysis of off-grid hybrid system," Renew. Sustain. Energy Rev., vol. 81, pp. 2217-2235, 2018.

[3] S. Sinha and S. S. Chandel, "Review of software tools for hybrid renewable energy systems," Renew. Sustain. Energy Rev., vol. 32, pp. 192-205, 2014.

[4] Y. Liu, S. Yu, Y. Zhu, D. Wang, and J. Liu, "Modeling, planning, application and management of energy systems for isolated areas: A review," Renew. Sustain. Energy Rev., vol. 82, pp. 460-470, 2018.

[5] A. J. A. Cardona, C. A. P. Chica, and D. H. O. Barragán, "Integrated Photovoltaic System Sizing and Economic Evaluation Using RETScreenTM for a Building of 40 Apartments," in Building-Integrated Photovoltaic Systems (BIPVS), Springer, 2018, pp. 35-46.

[6] M. G. Prina et al., "Multi-objective optimization algorithm coupled to EnergyPLAN software: The EPLANopt model," Energy, vol. 149, pp. 213-221, 2018.

[7] L. M. Halabi and S. Mekhilef, "Flexible hybrid renewable energy system design for a typical remote village located in tropical climate," J. Clean. Prod., vol. 177, pp. 908-924, 2018.

[8] M. Khan, R. Jidin, J. Pasupuleti, and S. A. Shaaya, "Micro-hydropower potential assessment and generation volatility due to seasonal climate," in 2014 IEEE International Conference on Power and Energy (PECon), , 2014, pp. 371-376.

[9] M. R. B. Khan, R. Jidin, J. Pasupuleti, and S. A. Shaaya, "Optimal combination of solar, wind, micro-hydro and diesel systems based on actual seasonal load profiles for a resort island in the South China Sea," Energy, vol. 82, pp. 80-97, 2015.

[10] M. Mohammadi, R. Ghasempour, F. R. Astaraei, E. Ahmadi, A. Aligholian, and A. Toopshekan, "Optimal planning of renewable energy resource for a residential house considering economic and reliability criteria," Int. J. Electr. Power Energy Syst., vol. 96, pp. 261-273, 2018.

[11] S. M. Dawoud and X. Lin, "Study of hybrid PV-wind energy system to isolated micro-grid," Indones. J. Electr. Eng. Comput. Sci., vol. 16, no. 2, pp. 221-231, 2015. 
[12] A. Waqar, S. Wang, Q. K. Mohsin, and M. Zahid, "Optimized Operation-Planning of a Microgrid with Renewable Sources and Vehicle to Grid," Indones. J. Electr. Eng. Comput. Sci., vol. 16, no. 3, pp. 401-408, 2015.

[13] N. A. Jefry and N. A. Zambri, "Suitability of Demand Response Program Equipped with Solar Energy in UTHM," Indones. J. Electr. Eng. Comput. Sci., vol. 6, no. 2, pp. 294-300, 2017.

[14] Y. Sawle, S. C. Gupta, and A. K. Bohre, "Socio-techno-economic design of hybrid renewable energy system using optimization techniques," Renew. Energy, vol. 119, pp. 459-472, 2018.

[15] A. Kaabeche, S. Diaf, and R. Ibtiouen, "Firefly-inspired algorithm for optimal sizing of renewable hybrid system considering reliability criteria," Sol. Energy, vol. 155, pp. 727-738, 2017.

[16] A. M. Patel and S. K. Singal, "Economic Analysis of Renewable Energy System for Electrification of Remote Rural Area having Scattered Population,” Int. J. Renew. Energy Res., vol. 8, no. 1, pp. 523-539, 2018.

[17] A. Lorestani and M. M. Ardehali, "Optimal integration of renewable energy sources for autonomous tri-generation combined cooling, heating and power system based on evolutionary particle swarm optimization algorithm," Energy, 2018.

[18] A. L. G. Noguera, L. S. M. Castellanos, E. E. S. Lora, and V. R. M. Cobas, "Optimum design of a hybrid dieselORC/photovoltaic system using PSO: Case study for the city of Cujubim, Brazil,”Energy, vol. 142, pp. 33-45, 2018.

[19] R. N. S. R. Mukhtaruddin, H. A. Rahman, M. Y. Hassan, and J. J. Jamian, "Optimal hybrid renewable energy design in autonomous system using Iterative-Pareto-Fuzzy technique," Int. J. Electr. Power Energy Syst., vol. 64, pp. 242-249, 2015.

[20] K. Roy, K. K. Mandal, A. C. Mandal, and S. N. Patra, "Analysis of energy management in micro grid--A hybrid BFOA and ANN approach," Renew. Sustain. Energy Rev., vol. 82, pp. 4296-4308, 2018.

[21] D. Feldman et al., "Photovoltaic System Pricing Trends: Historical, Recent, and Near-Term Projections-2013 Edition," Lawrence Berkeley Natl. Lab. Study, < emp. lbl. gov/sites/all/files/presentation. pdf>(accessed Sept. 20, 2013), 2013. 